\title{
PROFESSIONAL LIABILITY INSURANCE AND INCREASED CIVIL PROTECTION OF MEDICAL STAFF
}

\author{
Sodeh Hamed Tavasoli ${ }^{1} ه$ \\ ${ }^{1}$ Islamic Azad Research Sciences University, Iran
}

Received 4 November 2021

Accepted 16 December 2021

Published 31 January 2022

\section{CorrespondingAuthor \\ Sodeh Hamed Tavasoli, \\ shokoofeh_kazemi@yahoo.com}

DOI

10.29121/granthaalayah.v10.i1.2022 .4350

Funding: This research received no specific grant from any funding agency in the public, commercial, or not-for-profit sectors.

Copyright: (C) 2022 The Author(s). This is an open access article distributed under the terms of the Creative Commons Attribution License, which permits unrestricted use, distribution, and reproduction in any medium, provided the original author and source are credited.

\section{ABSTRACT}

Compensation for injuries caused by medical accidents is one of the main branches of insurance under the title of doctors' civil liability insurance. In the present article, we have decided to collect information on the income and expenses of doctors' professional liability insurances to obtain a community view of the coverage of this insurance and to explain the advantages and disadvantages of stakeholders and to propose practical solutions to expand coverage and increase insurance coverage.

In this study, information was collected from the Forensic Medicine Organization of Tehran Province about the amount of complaints and convictions of the medical staff in 1396 by a counting method in a researcher-made checklist and the amount of ransom that various medical professionals were required to pay in 1396 was estimated. Quality was calculated based on percentage and frequency and quantitative information was calculated based on mean and standard deviation.

Out of 4079 complaints, 3343 (52.5\%) were acquitted and 1731 (425\%) were convicted. The highest number of convictions was related to general surgery, general practitioners and dentists and the lowest convictions were related to traditional medicine, poisoning, nursing and pathology. Complaints from female patients were 2430 cases (59.6\%) and the rate of men complaints over time was 3076 cases (75.5\%). Between the two groups of medical staff who were required to pay ransom to patients and the group who were not negligent. There was no statistically significant difference in terms of gender. The highest amount of negligence was related to the complaints convicted in the Plastic Surgery Commission in the amount of 924,900,000 Tomans (Iranian currency) and the lowest amount of negligence was related to the complaints condemned in the Traditional Medicine Commission in the amount of $35,700,000$ Tomans. Considering the approximate number of 630/269 staff members and considering that if the insurer has spent on average $375 / 743$ Tomans for each limited liability insurance, a significant figure of $250 / 839 / 705 / 200$ can be calculated.

As a result, the obligation to insure medical staff requires a determinative. Therefore, it is appropriate for the Medical System organization, as the custodian and pioneer of supporting and providing services to the medical staff, to take action in this regard and to achieve this coverage.

Keywords: Complaint, Failure, Liability Insurance, Civil Liability, Medical Staff

\section{INTRODUCTION}

Today, health care is highly complex and patients during any treatment or any action to treat the disease may be exposed to some degree of harm. Compensation for damages and injuries caused by these accidents under the name of medical liability insurance of professional doctors and their staffs has a special place in most civilized countries and is one of the main branches of 
insurance. In fact, this type of insurance covers the insured medical and affiliated professionals against the claim of damages by the patient or the relatives. The history of professional liability insurance in the world goes back to the early nineteenth century. In our country, physicians' professional liability insurance was first provided by Iran Insurance Company in 1986, but unfortunately, despite this type of insurance, only a small number of medical professions insure their civil liability. Based on reviewing the law text in this subject, the benefits of insurance have been fully proven in various studies, and even been known necessary, but the coverage of this insurance is not acceptable. Due to the need to increase the reliability and trust and to change the

\section{MEDICAL PROFESSIONAL RESPONSIBILITY}

culture and the necessity to encourage of Medical professional responsibility, the most important purpose of this study is to explain these mechanisms and provide practical solutions to expand the professional liability insurance coverage of the medical profession.

It is now clear that a significant number of patients suffer some degree of permanent injury, hospitalization, increased hospital stays, and even death during treatment. According to the evidence, the most important causes of death are cardiovascular diseases, cancers, and accidents. While medical errors are among the most important causes of death and should be included in the list of the most important causes of death in the world.

Investigating the patient risk factors has shown that multiple causes are involved in the occurrence of errors and accidents occur when there is a combination of active and hidden errors. Active errors are usually associated with human factors and are the biggest threat to patient safety. The reasons for the main types of errors in terms of human factors are slips, inadvertent errors, mistakes, violations (violations) as well as hidden errors in the health care system, due to management decisions and organizational conditions. Research studies have shown that in developed countries, on average, $10 \%$ of all hospital admissions lead to adverse hospital events. In Iran, medical records and routine reports of health care workers are commonly used to record adverse events and medical errors. Also, accurate statistics on adverse events are not available and we have few reports, but it is predicted that the error rate is higher than what is reported. The increase in referral cases from physicians to the medical system could be a reason for this. According to statistics published by the Organization of the Medical System, 800 million medical services are provided to the people annually, and about 12,000 to 13,000 cases of medical errors are filed in the country. It is important to note that patient complaints are on the rise. As a result, if physicians and other medical professionals insure their liability against others, if for any reason they are held liable in the course of their professional activity, the insurer will compensate the damage with liability insurance. In addition, medical insurance, while reducing material damages, will also reduce moral damages and reduce the volume of lawsuits filed in the courts.

\section{RESEARCH METHODS}

In this research, the information was collected from Tehran Forensic Medicine Organization on the amount of complaints and convictions of the medical staff and determining the amount of compensation that different medical professions were required to pay in 2017. 
The research in this article includes the patients who were complained against the medical staff (including doctors, dentists, nurses, midwives, operating room technicians working in private hospitals, public, offices, outpatient and limited surgery centres (clinics), clinics and others in 1396. 4074 thousand complaints of medical staff were registered in the Forensic Medicine Organization of Tehran. The highest number of complaints from female patients and the highest number of complaints from medical staff were related to men working in the health system. The frequency distribution and frequency percentage of the plaintiff and the treatment staff are summarized in Table 1.

\begin{tabular}{|c|c|c|c|c|c|}
\hline & Gender & Frequency & Percent & $\begin{array}{c}\text { Valid Frequency } \\
\text { Percent }\end{array}$ & $\begin{array}{c}\text { Cumulative } \\
\text { Percent }\end{array}$ \\
\hline \multirow[t]{3}{*}{ patient } & Female & 2430 & 59.6 & 59.6 & 59.6 \\
\hline & male & 1644 & 40.4 & 40.4 & 100 \\
\hline & total & 4074 & 100 & 100 & \\
\hline \multirow[t]{3}{*}{$\begin{array}{c}\text { Treatment } \\
\text { staff }\end{array}$} & female & 998 & 24.5 & 24.5 & 24.5 \\
\hline & male & 3076 & 75.5 & 75.5 & 100 \\
\hline & total & 4074 & 100 & 100 & \\
\hline
\end{tabular}

Out of 4074 complaints against medical staff, 1731 (42.5\%) were convicted and $2343(57.5 \%)$ were acquitted. The highest number of convictions related to the field of surgery was 337 (16\%), 312 (14.8\%) to the general practitioner and 296 $(14 \%)$ to the dentists, and the lowest number of convictions were related to the fields of traditional medicine, poisoning 1 case $(0.04 \%) .2$ cases $(0.09 \%)$ and pathology 2 (0.09).

The mean age was 40.45 years in the group of medical staff who were negligent due to the error and in the group that was not neglected despite the error, it was 41.99 years and there was a statistically significant difference between the two groups in terms of There was an age variable between patients.

Table 2 Mean and standard deviation of the age variable of medical staff in the group of assigned and non-assigned negligence

\begin{tabular}{ccc}
\hline Group & Average Age & Standard deviation \\
\hline Assigned to the negligence treatment staff & 40.45 & 16.54 \\
\hline Not assigned to the negligence treatment staff & 41.99 & 19.36 \\
\hline
\end{tabular}

\section{DISCUSSION AND CONCLUSION}

In the case of professional liability insurance, the only thing that can be insured is the doctor's civil liability. There is no tolerance. Civil liability insurance is based on quasi-criminal or quasi-intentional liability in which the cause of damage due to carelessness and negligence causes loss of life and property to another person. In physicians' professional liability insurance, the insurer insures the physician's civil liability in relation to the medical profession to third parties, meaning that if the insurer due to error, mistake or negligence in performing professional services causes physical or mental injury or death of the patient And be legally responsible and obliged to compensate it, the insurer will be responsible for compensating it, so 
doctors and paramedics can deal with the financial consequences of being in the above situations by preparing a professional liability insurance policy.

In other words, according to the definition of "Physicians' Professional Liability Insurance" is the compensation of damages resulting from the insurer's professional liability to persons who due to errors, mistakes, negligence or negligence in diagnosis, treatment, surgery, and medical affairs in general. Suffer physical, psychological or death injuries. Prescription error, diagnosis and treatment error, radiology error, radiotherapy error, physiotherapy error, transmission error of infectious diseases such as hepatitis, AIDS, surgical error, anaesthesia, obstetrics, uterine rupture during curettage, intestinal rupture during surgery and overprescription Permissible amount of medication, not performing necessary and routine tests before surgery, not chest radiography, not using radiography to complete medical or surgical treatment for cancer, not examining the heart and not taking ECG before anaesthesia, not disinfecting treatment equipment that causes infection The disease becomes contagious.

A person committing suicide in a hospital as a result of negligence on the part of caregivers and the like will all be examples of medical malpractice under Article 3 of the General Conditions of Medical Liability Insurance. Therefore, if medical malpractice leads to damages and the guilty person has insured his liability, the insurer will take action to compensate the damages according to his obligation. The most important exceptions of this insurance are a) Non-profit damages, b: Treatment or surgery outside the insurer's specialty c: Treatment and surgeries outside of medical regulations or contrary to current laws, d: Damages due to ionizing or radioactive radiation, E) Liability arising from the use of intoxicants or the use of narcotics or sleeping pills.

It should be noted that with the expansion of medical liability and the complexity of medical services and the possibility of error, some countries have sought to make insurance compulsory. But in our country, based on the evidence of inclination, there is not much for medical liability insurance contracts. Data collected from the sources of statistics of the Organization of the Medical System during the years $1378-81$ indicated that on average only about $23 \%$ of physicians have obtained civil liability insurance.

\section{CONCLUSION}

The organization of the medical system (union), which since its establishment has sought to create and achieve lofty goals in order to protect patients' rights on the one hand and to raise the value and moral and human dignity, as well as to promote and advance the level of professional knowledge on the other hand, is very worthy and necessary. Is to act as a pioneer in providing insurance services, as a trustee and to achieve this coverage with its effective presence and explanation of the appropriate and comprehensive mechanism. A cover that is not currently even recognized as acceptable.

By encouraging and creating the necessary culture in various ways to enlighten the minds of this leading society, accepting the practice of insurance, which in many societies is obligatory and compulsory, requires determination and firm steps. It is possible that in this way he will face great obstacles from the ignorant aspirants of the position and narrow-mindedness, and regardless of the unkindness of some people, he will undoubtedly sincerely and uniformly seek to preserve this huge capital (albeit with spirituality and inner beliefs and social and political beliefs). And a seemingly different culture) the desired result can be achieved. 
It is worthwhile for the medical system organization, as the custodian and pioneer of supporting and providing services to the medical staff, to act and achieve full coverage of insurance services.

Due to the volume of this significant capital, in addition to full liability insurance coverage, it is possible in other areas such as appropriate investments in the field of holding desirable scientific conferences appropriate to the profession in the country and inviting domestic scholars and scholars of other countries (which themselves Increases the source of national capital), creating and receiving appropriate cultural, pilgrimage and tourism spaces to relax from time to time, cover annual membership fees and issue licenses for free, provide useful science in various ways, make great documents and figures Persistent medicine and resuscitation of other forgotten facilities are all possible if they are transparent, strictly supervised and, of course, compassionate.

\section{REFERENCES}

Austin M, DerkJ (2010) Lives lost, Lives Saved A Comfarative Analysis of Avoidable Deaths Hospitals graded by the leapfrag group. Retrieved from https://www.google scholar hospital safety core. Org / midia / file / Lives LostLive saved with paper

Bagherian M, AbadiH, Star M, Nejadnik M. (2021) Health Information Management : 1391, volume 9, Number $1: 101-109$

Fathi, Jila and Mohammadnejad Dariani, Ali Reza and Naseri, Ali Reza, (2015), An Analysis of the Types of Civil Liability Insurance in the Iranian Legal System, The First National Conference on Islamic Humanities, Qom, Retrieved from https : //civilica.com/doc/429350

Grober ED, Bohnen JM, (2005) Defining medical error Can J surg; 48: 39-44 pmid: 15757035 PubMed Google Scholar.

Hogn H. Zipfel R, Neuburger J, et al, (2015) Avoldablity of hospital deaths and association with hospital wide mortality ratios : retrospective case record review and regression analysis. BMI : 351. H32390. Abstract / FREE Full Text Google Scholar. Retrieved from https://doi.org/10.1136/bmj.h3239

Makary MA, Daniel M, (2016) Medical error- the third leading cause of death in the U.S BMI : 353 : 12139. Retrieved from https://doi.org/10.1136/bmj.i2139

Mehrnew.com. December 4, (2021), Retrieved from https://www.mehrnew.com

Moosazadeh M, Yegane MR, Aghaei l, Mahmoodi S, Mehrzad F, Amiresmaili MR. (2014) Medical adverse events during patient's hospitalization at training Hospitals in Kerman. Iranian J., Vol, 24, Issue 71 : 76-68

Otroil, Jean François, (1983), Theoretical and practical foundations of insurance. Translation : Abdolnasser Hemmati Aliq Dehghani (Second Edition, Central Insurance, Iran)

Reason JT, (2001) Understanding adverse events; the human factor. In Vincent C, ed. Clinical risk management : enhancing patient safety BMI : 9-30 Google Scholar

Salamatnews.Com. December 4, (2021), Retrieved from https : // www. Salamatnews. Com

Salehi H. (2014) Medical Professional Civil Liability Insurance Challenges, Neccessitics and Opportunies, Iran J Med Law. 8 (29) : 166 -131.

Spokesman, Rezvan, (1398), Professional Liability Insurance for Physicians, Nurses and Medical Staff, 8th International Conference of Law and Sustainable 
Professional Liability Insurance and Increased Civil Protection of Medical Staff

Development, Scientific Society, Shiraz, Retrieved from

https://civilica.com/doc/968917 